\title{
Optimisation as a Process for Managing River Ecosystems
}

\author{
E. J. Barbour ${ }^{\text {a,b*1 }}$, L. Holz, G. Kuczera ${ }^{\text {c }}$, C. A. Pollino ${ }^{\text {d, A. J. Jakeman }}{ }^{\mathrm{a}}$ and D. P. Loucks ${ }^{\mathrm{e}}$
}

${ }^{\mathrm{a}}$ Fenner School of Environment and Society, and National Centre for Groundwater Research and Training, Australian National University, Canberra, ACT 0200, Australia

${ }^{\mathrm{b}} \mathrm{School}$ of Geography and the Environment, University of Oxford, Oxford, OX1 3QY, United Kingdom

${ }^{\mathrm{c} S}$ chool of Engineering, University of Newcastle, Callaghan, NSW 2308, Australia

${ }^{\mathrm{d} C S I R O}$ Land and Water, PO Box 1666, Canberra, ACT 2615, Australia

${ }^{\mathrm{e}}$ School of Civil and Environmental Engineering; Institute for Public Affairs, Cornell University, Ithaca, NY, USA

*Corresponding author: emily.barbour@ouce.ox.ac.uk; em.barbour@gmail.com; Tel: +44

(0)1865285070; Fax: +44 (0)1865275885

Keywords: Ecosystem management, optimisation, water resources, uncertainty, decision making, review

\begin{abstract}
Optimisation can assist in the management of riverine ecosystems through the exploration of multiple alternative management strategies, and the evaluation of trade-offs between conflicting objectives. In addition, it can facilitate communication and learning about the system. However, the effectiveness of optimisation in aiding decision making for ecological management is currently limited by four major challenges: identification and quantification of ecosystem objectives; representation of ecosystems in predictive simulation models; specification of objectives and management alternatives in an optimisation framework; and evaluation of model results against actual ecological outcomes. This study evaluates previous literature in ecology, optimisation and decision science, and provides a strategy for addressing the challenges identified. It highlights the need for better recognition and analysis of assumptions in optimisation modelling as part of a process that generates and shares knowledge.
\end{abstract}

\section{Introduction}

River regulation and water extraction have played a fundamental role in development through benefits such as improved water security for towns and agricultures, flood mitigation, hydropower, and transportation. However, previous river management practices have caused significant changes in the structure and functioning of rivers and floodplains, as well as changes to flow patterns, water

\footnotetext{
${ }^{1}$ Present address: School of Geography and the Environment, University of Oxford, Oxford, OX1 3QY, United Kingdom
} 
quality and ecology (Poff et al., 1997; Bunn and Arthington, 2002; Poff et al., 2010). In response to the severe degradation of many of the world's rivers and the resulting social and economic cost, there has been a growing recognition of the importance of maintaining river systems and the incorporation of ecological objectives in river system management (Richter et al., 2006; Arthington et al., 2006; Acreman et al., 2014a; Poff and Matthews, 2013).

The greater recognition of the ecological value of river systems has introduced a number of challenges for the development of robust, adaptable and socially acceptable management strategies. Ecological objectives can be difficult to define and model, and often present a trade-off with other river management objectives such as agricultural yield or hydropower production. Optimisation is one method which can assist in identifying and evaluating alternative management policies, and trade-offs among multiple objectives. Whilst it has been widely applied to both water resource (see reviews by: Labadie, 2004; Nicklow et al., 2010 and Maier et al., 2014) and ecological management problems independently (e.g. Sarkar et al., 2006; Nicholson et al., 2006; Lee and Iwasa, 2014), fewer studies have utilised optimisation for the ecological management of river systems (e.g. Sale et al., 1982; Shiau and Wu, 2009; Suen at al., 2009; Yang and Cai, 2011; Rheinheimer et al., 2013).

The use of optimisation to aid decision making for ecosystems and other complex systems has been facilitated by the development of metaheuristics, a class of optimisation methods which use predefined rules to search for preferred solutions, and provide flexibility in problem definition. Metaheuristic methods overcame many of the restrictions on problem formulation and complexity required by earlier methods, such as linear and dynamic programming. However, the application of optimisation to increasingly complex systems has also required it to be redefined: from a tool used to find a single definitive solution; to one which aids in the exploration of different possible solutions, and facilitates learning and communication (Jacoby and Loucks, 1972; Liebman, 1976; Walters and Hilborn, 1978; Brill Jr, 1979).

The focus on finding a single 'optimal' solution was often appropriate for early applications of optimisation, which were largely simple engineering or logistical problems. However, the concept of optimality becomes less clearly defined for complex systems, where there are multiple, ill-defined and often conflicting objectives, which can only be partially represented in a modelling framework. The optimisation of these systems requires greater consideration regarding problem definition, model representation, and the impact of uncertainties and assumptions on actual management outcomes (Liebman, 1976; Haimes and Hall, 1977; Brill Jr, 1979).

The challenge of problem definition and representation of complex systems has been recognised and discussed in the context of planning and public policy since the 1960's and 70's (e.g. Hitch, 1960; Rittel and Webber, 1973; Liebman, 1976; and Brill Jr, 1979). These so called 'wicked problems' are applicable to ecological systems due to: inadequate knowledge of the system; lack of clear criteria by which to define objectives and measure outcomes; decisions having significant and often irreversible impacts; and each decision occurring in a unique context (Rittel and Webber, 1973; Metrick and 
Weitzman, 1998; Possingham et al., 2001; Failing and Gregory, 2003; Tear et al., 2005; Nicholson and Possingham, 2006; Nicholson and Possingham, 2007; Game et al., 2008; Hirsch et al., 2011; Game et al., 2014).

The use of optimisation introduces additional challenges through the need to specify objectives in a series of mathematical equations, and to develop an adequate model representation of the system such that 'optimal' solutions represent desirable outcomes to the actual problem (Ackoff, 1962; Haimes and Hall, 1977). This requires an understanding of how these formulations influence the resulting decisions, and consequently the management of the ecosystem (Wilson et al., 2009; Nicholson and Possingham, 2006). Whilst these challenges are well recognised, there has been limited discussion regarding the use of optimisation for ecological objectives in river basin management.

Defining ecological objectives is complicated by the existence of many and often conflicting social values regarding what is considered to be a 'preferred' environmental outcome. Preference for a particular outcome is also context dependent, and is influenced by factors such as a country's wealth, level of development, and competing requirements to fulfil basic needs. Added to this is the dynamic nature of many ecological systems, making it difficult to identify an ideal state in time and space. Representation of riverine ecological systems in a modelling framework requires an understanding of these dynamics and the relationship between river flow and ecological response, as well as the role of other influencing factors such as land management, climate, and disease (Shenton et al., 2012; Acreman et al., 2014b). It is therefore essential that the outcomes of any optimisation are critically evaluated in terms of the assumptions made, to identify what the likely actual outcomes will be. Assumptions can include conceptualisation of the problem, adequacy of the data, predictive capacity and suitability of the model for the decision being made, as well as set-up of the optimisation framework. Ideally, optimisation outcomes should be compared with actual ecological outcomes, to improve our understanding of ecological systems and improve the effectiveness of modelling and optimisation tools in aiding decision making.

Until recently, the majority of optimisation research has remained largely focused on algorithm development and application to different types of problems (Reed and Kasprzyk, 2009; Maier et al., 2014). Where optimisation has been employed to assist in ecosystem management, there has been little focus on the explicit challenges of ecological optimisation. Exceptions include Walters and Hilborn (1978), who reviewed different optimisation methods and approaches for ecological management considering uncertainty. More recently, Nicholson and Possingham (2006) examined the impact of translating management goals into specific mathematical objective functions. Whilst they did not use optimisation directly, they examined different objective function formulations for conservation planning, and the effect of these on preferred management strategies. Probert et al. (2011) demonstrated the effect of different optimisation algorithms (focusing on adaption to new knowledge), and different project objectives for conservation management. 
In the context of river system optimisation, Jager and Smith (2008) reviewed 29 optimisation studies which considered both hydropower and environmental criteria. The review identified the need for further research to adequately account for ecosystems in multi-objective optimisation, including: the need for a better understanding of flow-ecology relationships; tools to model such relationships; and the development of methods for valuing the environment.

In this synthesis, we draw upon literature from ecology, optimisation and decision science to discuss and evaluate different approaches for the optimisation of riverine ecosystems. The paper discusses four key challenges throughout the optimisation process which are considered essential for effective river basin management:

1. Ecological objectives - defining ecological objectives for optimisation studies and the role of social values.

2. Ecological models - limitations and strengths of different types of models used for river system optimisation

3. Optimisation of ecological objectives - challenges in defining objective functions and decision variables; and

4. Ecological outcomes - how well modelled results are evaluated in terms of actual outcomes.

In the following sections each of the four challenges is discussed through critical evaluation of previous studies. The paper concludes with an overview of key outcomes and recommendations.

\section{The art of defining ecological objectives}

Defining objectives is one of the first steps in any study or management activity. In the case of ecological systems, this presents a major challenge, yet is generally given insufficient attention in optimisation studies. Setting ecological objectives is largely a subjective process involving social values as much as scientific knowledge, and these values often differ between stakeholders and experts (Voinov and Bousquet, 2010; Liebman, 1976; Davis and Slobodkin, 2004). The selection of who to involve in defining objectives can therefore ultimately influence the final management outcome.

Identifying broad, high level goals for ecological management is important in providing context and justification for a particular study, yet these require translation into clear, specific, quantifiable objectives which can be used within the modelling process and to measure the success of outcomes (Metrick and Weitzman, 1998; Richter et al., 2003; Tear et al., 2005; Palmer et al., 2005; Nicholson and Possingham, 2006; Fischer et al., 2009). It is essential that the assumptions required in translating broad goals into specific objectives are transparent, well recognised, and inclusive, in order to achieve the best possible management outcomes with minimal unintended consequences. Assumptions may 
include focusing on a desired ecological state, or a particular species at a specific timeframe or location (e.g. Nicholson and Possingham, 2006). Identifying specific objectives can assist in selecting the most appropriate modelling and optimisation approaches, and enabling optimisation outcomes to be evaluated. Conversely, limitations in model, optimisation and implementation capabilities need to be considered to ensure objectives are realistic and achievable.

Previous optimisation studies have focused on human water objectives which are often specific and well known. For example, basic water needs can be roughly estimated on a per capita basis dependent upon the time of day, temperature and other climatic variables. Similar estimates can be made for other water users such as industry, agriculture and hydropower. In contrast, defining ecological objectives and objectives incorporating social values (such as cultural flows - see Jackson, 2006; Finn and Jackson, 2011; Jackson et al., 2015) is far less straightforward.

Ecological systems include multiple species which respond to external drivers, complex internal interactions and have lags in response. Ecosystem needs and optimal states are difficult to identify, being highly variable and often dependent on antecedent states, as well as operating at different scales (Holling, 1973). Whilst defining objectives for a single species, habitat or population may be quantifiable, at a community scale ecosystem needs become harder to define, as they depend on composition, interactions, redundancies and dependencies across time and space (Poiani et al., 2000; Naiman et al., 2008). At ecosystem scales, consideration of additional factors such as connectivity between habitats and meta-populations is required, and hence it can be harder still to identify what constitutes an ideal state. Ecosystems are constantly in flux, where their composition may change over time as biota evolve and environmental conditions change (Cropp and Gabric, 2002), and questions of whether one type of composition is more desirable than another become largely subjective.

Given the challenge of defining ecological objectives, the use of high level, all-encompassing goals that focus on the concept of ecosystem health has been widely adopted. Whilst this approach has a number of advantages such as being holistic, and engaging the public through the metaphor with human health (Rapport, 1989; Boulton, 1999), it also has a number of disadvantages. Ecosystem health is a largely subjective concept which is dependent upon society's values, yet is often applied with the misleading assumption that it is objective and measurable (Steedman, 1994; Wicklum and Davies, 1995; Davis and Slobodkin, 2004). Consequently, there has been much debate around the meaning and usefulness of ecosystem health as a management objective (e.g. Suter, 1993; Steedman, 1994; Wicklum and Davies, 1995; Lancaster, 2000; Lackey, 2001), as well as more specifically around river health (e.g. Karr, 1999; Boulton, 1999; Norris and Thoms, 1999).

Defining socially acceptable, ecologically robust and relevant objectives therefore remains a challenge, as further demonstrated in the following section.

\subsection{Defining ecological objectives for river system optimisation}


A selection of previous optimisation studies which examined ecological objectives for river system management were analysed in terms of the ecological objective, modelling method and optimisation approach adopted. The papers examined spanned the period from 1982 to 2015, and reflected changes in river system management and optimisation approaches, as well as changes in available methods and technology. Papers were selected based on the use of different approaches for ecological management in river systems with varying levels of complexity. They included different types of ecological objectives and models such as the use of flow based metrics, species based flow preferences, and economic valuation. The papers covered different aspects of river system management, including reservoir operations and trade-offs with non-ecological objectives, environmental flow allocations, and the use of flow control structures for wetlands and floodplains. Furthermore, they adopted different optimisation approaches including classical and metaheuristic methods, with different formulations of single or multiple objectives. In covering this range of studies, the synthesis aims to identify some of the key trends and differences in methods, whilst not claiming to be an exhaustive coverage of the optimisation literature.

Papers were firstly evaluated using two main criteria: (1) the type of ecological objective used, which is indicative of a particular approach to ecological management; and (2) how specific the objective is, which influences what assumptions are needed for quantitative modelling and optimisation. Both of these criteria can influence the modelling and optimisation process, and hence impact upon the resulting management strategies. These are discussed in more detail below.

\subsubsection{Types of ecological objectives}

Based on the papers examined, two main types of ecological objectives were identified: achieving hydrological metrics; and targeting ecological needs directly. Hydrological metrics are frequently used for defining ecological water needs in river system models and optimisation. This flow-based approach relies on identifying key components of the hydrograph, such as events of a particular magnitude, duration and seasonality, to meet the ecological needs of a river system (Poff $e t$ al., 1997). Where indicators aim to represent all aspects of a natural (unimpaired) flow regime, the water requirements of multiple species and locations can be met. This type of approach can be easy to implement where there is little ecological data or knowledge of which ecosystems are most highly valued, and can be quantified using flow data. Examples of hydrologic metric-based objectives include minimising hydrologic alteration (Shiau and $\mathrm{Wu}, 2006$; Yin et al., 2012; Shiau and $\mathrm{Wu}$, 2013), maintaining the variability of the natural flow regime (Dittmann et al., 2009), maximising instream flow benefits (Sale et al., 1982), and providing an ecological flow regime (Suen and Eheart, 2006).

Challenges in using hydrological metrics include defining appropriate flow indicators that capture key ecological functions and achieve the intended ecological outcome; and identifying an acceptable deviation from baseline values (Richter et al., 1997). What constitutes an appropriate 
baseline can also be debated, given some ecological communities that have adapted to modified flow regimes may be highly valued. Consequently, returning these systems to a more natural state may not be socially acceptable (e.g. Rapport, 1989; Hobbs et al., 2006; Hobbs et al., 2009; Acreman et al., 2014b).

The second type of objective focuses on directly targeting ecological needs (or assets), and identifying the flow required to meet these needs. Environmental water requirements are typically defined for a particular ecological attribute (e.g. species, communities) at a defined location(s). Examples of these objectives (as defined in the papers examined) include: meeting the flow needs of native fish species (Suen et al., 2009); maximise riverine fish biodiversity (Tsai et al., 2015); meeting the water requirements of a range of flora and fauna (Szemis et al., 2012; Szemis et al., 2014); meeting downstream ecosystem needs (Yin et al., 2012); and meeting in situ uses (Grafton et al., 2011).

A challenge of this approach is the reliance on selecting a range of indicators that are representative of the diversity of water requirements within an ecosystem (Davies et al., 2010; Bunn et al., 2010). The approach can also require prioritising between different species and locations given it may not be feasible to specify objectives for all ecological components, thereby introducing tradeoffs. Additionally, the ecological flow requirements of key species may not be well understood.

\subsubsection{Level of specificity}

In addition to distinguishing between hydrological metrics and ecological needs objectives, it can be seen from the examples above that some objectives are more general and holistic (such as meeting downstream ecosystem needs), whilst others are much more specific (such as meeting the flow requirements of specific flora and fauna). This distinction has important implications for modelling and optimisation. More general objectives can be informative in providing a holistic, overall goal, and can assist in engaging with decision makers and stakeholders. However, a number of assumptions are required to translate these into quantitative objectives which can be modelled and optimised (Metrick and Weitzman, 1998; Nicholson and Possingham, 2006). These assumptions can involve value judgements and can impact upon the resulting management solutions, yet are rarely discussed in optimisation studies.

More specific objectives such as to 'return the natural flow regime of key components of river ecosystems in terms of flood timing, flood duration, and inter-flood period' (Higgins et al., 2011), or to 'design optimal seasonal flow patterns for salmon' (Jager and Rose, 2003) can provide greater detail regarding what will actually be modelled and optimised.

Defining specific objectives is often more challenging at larger temporal and spatial scales which encompass multiple ecological and non-ecological components and multiple stakeholder perspectives. However, it is equally relevant for smaller scale analyses focusing on individual species or communities, where assumptions are still required to define quantitative functions. 


\subsection{Evaluation and recommendations for defining ecological objectives}

All but two of the papers examined contained limited discussion of the assumptions and implications of the specified ecological objectives, highlighting a gap in the current literature. Exceptions include Dittmann et al. (2009), who identified that maintaining natural flow variability did not encompass all biological requirements for water, but provided a first step approach. Rheinheimer et al. (2013) identified that the use of minimum flow objectives did not capture important higher natural flows which are also ecologically important.

Despite the subjectivity of defining objectives and the reliance on social values, none of the papers referred to stakeholder engagement in the derivation of objectives. Rheinheimer et al. (2013) referred to stakeholders advocating for greater consideration of the natural flow regime in the study area as motivation for the analysis, although any direct involvement in the modelling and optimisation was not discussed. Involving stakeholders in the derivation of objectives is considered essential for effective and transparent management of ecological systems (Loucks, 2006).

The identification of appropriate, specific and measurable objectives within a broader environmental context is important for ensuring the modelling and optimisation framework is most effective in aiding management decisions. This requires careful consideration of the desired ecological outcome, and explicitly stating the assumptions made to model the identified objectives.

\section{How well can we model ecological systems for river system optimisation?}

Although optimisation can assist in identifying management strategies for meeting ecological objectives, the ability to do so is dependent upon how well the model represents the ecological system. Solutions identified as being 'optimal' may be infeasible and suboptimal in reality if the problem is not appropriately represented. However, an iterative process of evaluating model solutions and model behaviour through optimisation can assist in improving knowledge of the system. This section evaluates the advantages and disadvantages of different types of ecological models used in river system optimisation.

The ecological models examined were classified into two groups: (1) hydrological methods and (2) species preferences. These categories align with the two types of objectives described in Section 2.1.1. Hydrological approaches were the most frequently used for representing ecological systems, and included the natural flow approach as well as other types of flow metrics. The use of these two approaches in river system optimisation is explored in the following two sections.

\subsection{Hydrological methods}

It has been well established that flow is one of the key determinants of riverine and floodplain structure, function, and ecology (Poff et al., 1997; Bunn and Arthington, 2002; Arthington et al., 
2006). The natural flow approach provides a holistic way of capturing ecological water requirements. It is reliant on the use of flow metrics to describe the key features of the flow regime which are ecologically significant. The natural flow approach can be used for both instream and overbank flows, but has been predominantly applied to instream requirements.

One of the most commonly used set of metrics for evaluating the environmental impacts of river regulation is the Indicators of Hydrologic Alteration (IHA) method (Richter et al., 1996). IHA includes 32 indicators based on the magnitude, timing, frequency, duration and rate of change in flows. IHA is often used in conjunction with the Range of Variability Approach (Richter et al., 1997) which provides a method for identifying an acceptable deviation in IHA values between baseline and altered flows.

The IHA and RVA methods are also frequently used in the optimisation of ecological objectives (e.g. Dittmann et al., 2009). Variations on the IHA and RVA approach include different methods of aggregating indicators to give greater sensitivity to high scoring values (with high levels of alteration) (Shiau and $\mathrm{Wu}, 2006$ ); and the use of frequency histograms to consider variations of indicator values within and outside a target range, thereby overcoming limitations of the RVA approach (Shiau and $\mathrm{Wu}, 2008)$. Four alternative flow metrics were used by Yin et al. (2012) along with a modified RVA approach, whilst Yang and Cai (2011) used IHA in combination with fish data to generate a fish diversity index.

An alternative set of indicators (the Taiwan Ecohydrology Indicator System, TEIS) has been developed using fish data to create fuzzy and non-fuzzy membership functions using the intermediate disturbance hypothesis (which assumes an average level of variation in flow metrics is desirable) (Suen and Eheart, 2006; Suen et al., 2009). A flow alteration metric was also developed by Hurford et al. (2014) to focus on seasonal variation between regulated and unregulated flows.

IHA and TEIS metrics use daily flow data to evaluate ecological impact, with fewer studies examining sub-daily impacts due to limited availability of suitable metrics and data (Olivares et al., 2015). Sub-daily alterations in flow due to hydropower and dam operations can have significant impact on downstream ecosystems which is not reflected in daily flow metrics (Cushman, 1985; Zimmerman et al., 2010; Haas et al., 2014; Bevelhimer et al., 2015). Optimisation studies which consider sub-daily ecological impacts include Shiau and Wu (2013), who explore the use of hydrological metrics at different temporal scales including sub-daily, daily, seasonal, annual, and inter-annual scales. Sub-daily impacts are assessed using the Richards-Baker flashiness index (Baker et al., 2004), which is also used by Olivares et al. (2015) to analyse the economic and environmental efficiency of sub-daily flow constraints for hydropower operation.

The use of the natural flow approach in modelling ecological systems requires consideration of: (1) whether natural flow based indicators are appropriate for the particular case study; (2) how to define the natural flow hydrograph, such as what length of time should be considered, and how longterm variability (such as wet and dry periods) should be captured; (3) the location at which actual 
flows are measured (typically just downstream of the dam), and how these releases are influenced by additional non-environmental releases and extractions downstream; (4) how to compare indicators representing a natural and altered flow regime; and (5) how to meaningfully aggregate the indicators.

In many river basins, identifying a time series of natural flows is limited by the extent of human impact. Even where there has been minimal infrastructure development or extractions, changes in land use can significantly impact on rainfall-runoff patterns. In areas of highly variable precipitation, flow records of sufficient duration to capture this variability may not exist. This is further complicated by the effects of climate change, and the need to distinguish between natural variability and anthropogenic induced long term change.

Other hydrologic approaches used in previous studies include the setting of flow targets. These targets include static minimum flows (e.g. Yeh and Becker, 1982; Wang et al., 2009; Rheinheimer et al., 2013); static seasonal flows (e.g. Tilmant et al. (2010) used 50\% of pre-development seasonal flows as a target); monthly flow targets (Xevi and Khan, 2005); and optimal dry periods (Grafton et al., 2011). Whilst the effectiveness of these targets is very much dependent upon the particular ecosystem and management objectives, the implications of such approaches is worthy of investigation. For example, minimum flows can provide for instream biota during critical periods, but do not provide the variability required by many species. In addition, minimum flows can have a detrimental impact by reducing variability, and are often of insufficient magnitude to meet floodplain and wetland water requirements. The use of monthly flow targets enables some intra-annual variability to be maintained, which may be adequate in some systems with little inter-annual variability but are insufficient in highly variable systems (Poff et al, 1997).

Hydrologic targets have been used in optimisation studies to evaluate the economic impact of different management alternatives. For example, Grafton et al. (2011) specified optimal durations for 'dry' periods, and applied an exponential cost function where this was exceeded. Tilmant et al. (2010) calculated the economic value of flows within a specified range using a two-step marginal benefit function. Rheinheimer et al. (2013) applied an economic value to unmet minimum flow requirements, based on relative value to hydropower.

The benefits of using economic valuation methods include ease of comparison with nonenvironmental objectives valued in monetary terms, which can assist in engaging policy makers and generating greater awareness of environmental values (Costanza et al., 1997). However, economic valuation can be highly subjective and result in the undervaluing of resources (e.g. Costanza et al., 1997; Fisher et al., 2009). This is particularly true for environmental flows, which have intrinsic and indirect value through supporting ecological function and processes, rather than providing more direct services such as water supply for domestic and agricultural purposes. 
Species preference-based methods are often used when umbrella or keystone species are targeted, or used to represent wider environmental water requirements. However, the selection of appropriate indicator species and locations that are representative of the entire system (or specified objectives) is critical to the success of this approach (Rogers et al., 2012). Where multiple indicator species and locations are used, the method of aggregation requires careful consideration and raises the question of the relative importance of one species/location compared with another (Davies et al., 2010). This approach can also be significantly more data intensive, which may further limit study size and number of species/locations.

The Murray Flow Assessment Tool (MFAT) is an example of a species preference tool, which was developed in Australia for assessing the condition of habitat for fish, waterbirds and vegetation for the River Murray (Young et al., 2003). MFAT consists of a set of preference curves for depth, duration, magnitude, frequency and rate of change, which relate flow to an index between 0 and 1 to represent the health of a particular species. Each preference curve is then combined to produce an overall score. Higgins et al. (2011) used MFAT to assess the location and operation of weirs and regulators to improve ecological outcomes. MFAT was also used by Szemis et al. (2012) to compare different environmental flow allocations, and demonstrate the sensitivity of solutions to different species and weightings. In Szemis et al. (2014), MFAT was used to evaluate the ecological outcome of different dam releases allowing for adaptive information on available environmental allocations.

Other examples of species preference methods include the Weighted Usable Area (WUA) approach, which was used by Sale et al. (1982) to develop a habitat condition index for different fish species. Tsai et al. (2015) used artificial neural networks to generate a relationship between flow based metrics (using TEIS) and fish diversity. Fish diversity was calculated using the Shannon Index (Shannon, 1948), which compares the number of individuals of different species relative to the total number of all individuals. Jager and Rose (2003) and Jager (2014) used population based models to relate salmon survival to flow releases, considering spatially explicit habitat and different life stages.

\subsection{Evaluation and recommendations for modelling ecological systems for river system optimisation}

The majority of papers which were examined identified limitations and uncertainties associated with their modelling approach. For example, Szemis et al. (2012) used sensitivity analysis to identify the impact of different species, locations, and method of aggregation. Tsai et al. (2015) refer to the uncertainty in estimating ecological response, with fish biodiversity not representing all ecological requirements. Olivares et al. (2015) refer to the lack of evidence regarding sub-daily flow indicators and thresholds for estimating ecological impacts. However, a limited number of studies undertook a comprehensive evaluation of the impact of model behaviour on ecological objectives, despite the need for rigorous assessment of assumptions being well recognised (e.g. Jakeman et al., 2006).

Given the considerable uncertainty involved in representing ecological systems in a quantitative model, greater consideration is needed in identifying and testing model behaviour and implications for 
optimisation outcomes. This was demonstrated by Norton and Andrews (2006), who found that MFAT habitat condition scores were sensitive to the method of aggregating individual preference curves. A wide variety of methods exist for model assessment, including comparing model output with observed data, sensitivity analysis, error propagation, Bayesian analysis, scenario analysis, and multi-model simulation (see for example Jakeman et al., 2006; Refsgaard et al., 2007; Matott et al., 2009; and Bennett et al., 2013). In addition, optimisation can also be applied as a process for better understanding model behaviour and system understanding (Jacoby and Loucks, 1972; Liebman, 1976).

Model development can be aided by frameworks such as the Ecological Limits of Hydrological Alteration (ELOHA) (Poff et al., 2010), which provides a strategy for improving the local relevance of flow alteration - ecology relationships through using local hydrologic and geomorphologic data. Stakeholder input to defining ecological objectives can also guide which indicators are most appropriate and what level of alteration is considered acceptable (e.g. SUMHA, Pahl-Wostl et al., 2013).

\section{Representing ecological requirements in an optimisation framework}

The use of optimisation to evaluate ecological objectives requires the identification of appropriate optimisation algorithm(s), objective function(s) and decision variables. Each of these is evaluated below with reference to previous studies.

\subsection{Optimisation algorithms for ecological management in river systems}

Metaheuristics and their hybrid variations are being increasingly used in river system optimisation, due to their greater flexibility and capacity to handle complex systems (e.g. Maier et al., 2014). A number of river system studies have used metaheuristics to examine trade-offs between ecological and non-ecological objectives (e.g. Suen and Eheart, 2006; Suen et al., 2009; Dittmann et al., 2009; Yang and Cai, 2011; and Tsai et al., 2015). In comparison, there appear to be fewer applications of metaheuristics in studies focusing on ecological systems in conservation planning (Sarkar et al., 2006; Possingham et al., 2001). Although a number of limitations remain in the use of metaheuristics (see Maier et al., 2014), the capacity to incorporate more complex models and explicitly represent multiple objectives makes them well suited to ecological models and objectives.

As an alternative to metaheuristic optimisation methods, earlier 'classical' methods place restrictions on problem formulation and level of complexity, and hence often require simplifications to model structure and objective functions. Developed prior to metaheuristic methods, they retain the advantages of being capable of greater efficiency, providing exact solutions for linear problems, and handling many decision variables. Classical methods can therefore provide an effective approach for problem formulations and objectives which do not require the greater flexibility of metaheuristic 
methods, such as in cases where there is insufficient knowledge to support complex models of environmental systems (e.g. Biegler and Grossmann, 2004; Labadie, 2004). A number of optimisation studies have utilised classical methods to examine ecological objectives, including Yeh and Becker (1982), Sale et al. (1982), Shiau and Wu (2006), Xevi and Khan (2005), Ringler and Cai (2006), and Rheinheimer et al. (2013).

\subsection{Objective functions}

Optimisation requires user-defined objectives to be specified in a mathematical format. This can be particularly challenging in defining ecological objectives. Formulation of objective functions typically requires the aggregation of values over time and space, with the method of aggregation having the potential to significantly impact on the resulting optimal solutions. This includes: aggregation of time series values such as through summation, averaging, or selecting a subset of values exceeding a threshold; aggregation over different locations; as well as aggregation of multiple objectives. Aggregation can also involve the use of weights, which introduce further subjectivity and can bias solutions that more closely match a desired outcome.

Whilst there has been some evaluation of different aggregation methods for combining objectives, no thorough assessment of the effect of objective function formulation on river system management outcomes has been identified. Examples of evaluation which has been undertaken include: Higgins et al. (2011), who discussed the use of multiplication for different indicators to give the lowest scoring value a greater impact; and Sale et al. (1982), who maximised a minimum habitat value based on the assumption that fish production is controlled by the most limiting conditions.

There has been greater focus on objective setting in conservation management (e.g. Ellison, 1996; Wilson et al., 2009; Nicholson and Possingham, 2006). For example, Nicholson and Possingham (2006) evaluated the performance of three conservation management scenarios using seven different objective function formulations, all considering risk of extinction. All but two of the seven objective functions returned different rankings of preferred management scenarios, demonstrating the significance of objective function formulation on resulting solutions.

Of the papers examined for this synthesis, there were four main types of ecological objective functions used: (1) Maximise/minimise totals or averages; (2) Maximise/minimise differences between actual and target values; (3) Objectives framed as constraints; and (4) Maximise a minimum/minimise a maximum. The likely effect of these formulations of optimisation results and ecological outcomes is discussed below.

\subsubsection{Maximise/minimise totals or averages}

Maximising or minimising a total or average value has the effect of giving greater focus to large increments in values. In the case of maximisation, greater total or average scores may be achieved through increasing a small subset of individual scores by large amounts, rather than increasing all 
scores by small amounts. Whilst this effect can be influenced by scale and how the scores are defined, there is potential for short periods of time with 'good' ecological outcomes being given priority over maintaining condition above critical values. As an example of this type of objective function, Equation 1 was adopted by Szemis et al. (2012) and Szemis et al. (2014) to calculate ecological condition based on the MFAT model, for different species, locations, and years:

$$
\max \left(\sum_{i=1}^{q} w_{1 i} \sum_{r=1}^{s} w_{2 r} \sum_{v=1}^{K} \frac{w_{3 v} E_{i, r, v}}{Y_{K}}\right)
$$

where

$$
\begin{array}{lll}
\mathrm{E}_{\mathrm{i}, \mathrm{r}, \mathrm{v}} & = & \text { indicator for ecological asset } i, \text { indicator type } r, \text { in the time interval } v \\
Q & = & \text { total number of wetlands, floodplains and river reaches } \\
\mathrm{S} & = & \text { total number of indicators } \\
\mathrm{Y}_{\mathrm{K}} & = & \text { years, ranging from } 1 \text { to a total of K years } \\
w & = & \text { weights }
\end{array}
$$

In addition to Equation 1, Szemis et al. (2014) included a second objective function to minimise the difference in environmental flow operations between time steps accounting for updated environmental allocation forecast information. This objective function used a similar method of aggregating over time and management alternatives.

As an alternative, Grafton et al. (2011) combined environmental cost and irrigation profit into a 'social return' index. This social return was then summed for each year over the total simulation period using a discount rate to provide an expected net present value which was maximised. The use of a discount rate to apply greater weight to more recent outcomes may have advantages in placing more focus on managing environmental assets in the short term, when there is greater certainty about ecological requirements. However, ecosystems operate on long term cycles, hence reducing water delivery and sacrificing short term condition for long term outcomes may provide greater overall benefit.

\subsubsection{Maximise/minimise differences between actual and target values}

The success of any approach based on outcomes relative to a target relies greatly on how the target is defined. The same principle applies when setting constraint values. Objective functions which compare actual values with target values summed over time focus on deviations from this target. For example, Yin et al. (2012) used the RVA approach to minimise the difference between the number of years each indicator value fell within a target range for an altered hydrograph compared with a natural hydrograph, as shown in Equation 2: 


$$
D=\frac{1}{H} \sum_{m=1}^{H}\left|\frac{N_{o, m}-N_{e, m}}{N_{e, m}}\right| \times 100 \%
$$

where

$$
\begin{aligned}
& \mathrm{D}=\text { degree of flow regime alteration } \\
& \mathrm{m} \quad=\quad \text { hydrological indicator, with a total of } \mathrm{H} \text { indicators } \\
& \mathrm{N}_{\mathrm{o}, \mathrm{m}}=\text { number of years where hydrological indicator falls within the target } \\
& \text { RVA range } \\
& \mathrm{N}_{\mathrm{o}, \mathrm{m}}=\text { expected number of years where the hydrological indicator falls within } \\
& \text { the RVA target range }
\end{aligned}
$$

Whilst the approach used by Yin et al. (2012) recognises that even the natural hydrograph may not always meet target values, it penalises the number of years which fall outside the natural range irrespective of whether the number falls short of, or exceeds the natural range. This raises the question of whether a modified flow regime can (and should) be able to perform 'better' than natural based on these indicators. As identified by Shiau and Wu (2009), values falling outside the target range are treated the same irrespective of their magnitude, as are those within the target range. Indicators are combined by averaging their values, which assumes all indicators have equal value.

Higgins et al. (2011) also minimised the difference between altered and natural flows but using species preference curves from MFAT for flood timing, duration and inter-flood period using Equation 3. Differences between natural and actual values were squared, giving greater emphasis to larger differences. Separate MFAT curves were multiplied together, which gives greater weight to smaller scores as changes become proportional rather than additive (for example, an increase in score from 0.2 to 0.4 has the same outcome as increasing a score from 0.4 to 0.8 ). In optimisation, this may be advantageous in reducing the times at which the ecosystem is in a poor condition. However, it also means that the same effort is used to reducing small differences between actual and natural indicators compared with larger differences.

$$
\begin{aligned}
\operatorname{Min} \mathrm{Z}= & \sum_{m c} \sum_{k \in K} \sum_{l \in L} M F T_{k}^{m c} \cdot\left(F T_{k, l}^{m c}-N F T_{k, l}^{m c}\right)^{2} \\
& \cdot \sum_{m i} \sum_{k \in K} \sum_{l \in L} M F D_{k}^{m i} \cdot\left(F D_{k, l}^{m i}-N F D_{k, l}^{m i}\right)^{2} \\
& \cdot \sum_{m i} \sum_{k \in K} \sum_{l \in L} M I P_{k}^{m i} \cdot\left(I P_{k, l}^{m i}-N I P_{k, l}^{m i}\right)^{2}
\end{aligned}
$$

where

$$
\begin{array}{ll}
m c & =\text { calendar month } \\
k \in K & =\text { ecological indicator (e.g. waterbirds) } \\
l \in L & =\text { river section }
\end{array}
$$




$$
\begin{array}{ll}
m i & =\text { inundation duration (months) } \\
M F T_{k}^{m c} & =\text { ecological health response for month } m c \text {, river section } l \text { and indicator } k \\
F T_{k, l}^{m c} & =\text { total area of indicator } k \text { which has sufficient volume of water in month } m c \\
N F T_{k, l}^{m c} & =\text { total area of indicator } k \text { which has sufficient volume water in month } m c \text { for } \\
& \text { the natural hydrograph } \\
F D_{k, l}^{m i} & =\text { total area inundated for a duration of } m i \text { months for river section } l \text { and } \\
I P_{k, l}^{m i} & \text { indicator } k \\
& =\text { total area with an inter-flood period of } m i \text { months for river section } l \text { and } \\
& \text { indicator } k
\end{array}
$$

The way in which differences in target values are aggregated is another key consideration where a sequence of failures in meeting a target in multiple consecutive years has a different outcome compared with a few poor years interspersed amongst a number of good years.

\subsubsection{Objectives framed as constraints}

Some studies specify ecological targets as constraints rather than independent objective functions. The effectiveness of this approach relies on how this target is defined. The advantage of this method is that a particular ecological outcome is achieved for all management solutions considered. However, it also means that the outcome is unlikely to ever be better than this minimum value, particularly if it conflicts with the objective(s), as the optimiser will have no incentive to find solutions with greater values. This raises the question of what level of ecological outcome is considered acceptable.

Ecological constraints were used by Yeh and Becker (1982), who used a minimum flow constraint for fish protection. The value of this constraint was not discussed, with the implication that it would be identified external to the optimisation process. Constraint values were varied to develop a trade-off curve with other objectives. Olivares et al. (2015) also used constraints to represent ecological requirements using a combination of minimum flows and maximum ramping rates for hydropower generation (which control the difference in flow at the current time step compared with the previous time step). Multiple solutions were obtained by varying constraint thresholds.

\subsubsection{Maximise a minimum/Minimise a maximum}

Similar to the constraint method, maximising a minimum value places emphasis on avoiding worst case conditions rather than focusing on maximising optimal conditions. However, unlike the constraint method, this has the advantage of not setting a fixed minimum value, and provides incentive to improve this minimum value as much as possible. In a multiple objective setting, it also allows trade-offs to be generated, which is not possible when objectives are specified as constraints. 
This form of objective function was used by Sale et al. (1982) to maximise the minimum habitat suitability condition, calculated using WUA (Equation 4). This has the advantage of reducing the likelihood of any critically poor habitat condition from occurring. The disadvantage is that short periods of low habitat availability may be tolerated by some species, and it gives less incentive for the optimiser to maximise good conditions at other times.

\section{$\operatorname{Max} z$}

subject to

$$
h_{j}\left(\hat{q}_{t}\right)-p_{j, t} \cdot z \geq 0 \quad \forall t=1 \text { to } T \quad j=1 \text { to } J
$$

where

$h_{j}\left(\hat{q}_{t}\right)=$ percent of optimal WUA for life stage $j$ based on discharge $\hat{q}_{t}$ determined by dam operations

$p_{j, t} \quad=$ coefficient to indicate when life stage $j$ is present in period $t$

$z \quad=$ minimum habitat value for all life stages and periods

$J \quad=$ total number of life stages modelled

\subsection{Decision variables}

The choice of decision variables can also greatly influence which management solutions are considered optimal. This was demonstrated by Kasprzyk et al. (2012) for a water supply case study, where different sets of decision variables were selected based on a sensitivity analysis, and their impact on management strategies compared.

The number and type of decision variables used can influence the degree of variability and control captured within the management strategies. For example, Sale et al. (1982) used 12 decision variables to define the target reservoir volume for each month over a one year period, whilst Shiau and $\mathrm{Wu}$ (2009) also used 12 decision variables to define monthly environmental flow releases. In comparison, Suen and Eheart (2006) and Suen et al. (2009) used 36 decision variables to represent 10 day release volumes, thereby deriving operating rules at a finer resolution. At the other extreme, Grafton et al. (2011) defined a yearly environmental release, but over a simulation period of over 100 years. In this case, any representation of intra-annual variability would have required a significant increase in the number of decision variables.

A different approach was adopted by Dittmann et al. (2009), who defined a piecewise linear function to dictate what percentage of the inflow should be released at different storage levels over a 39 year simulation period. By defining decision variables which are a function of the inflow, fewer variables can be used with a greater capacity to incorporate both intra-annual and inter-annual variability. This becomes particularly useful when multi-year simulations are used. 
4.4 Evaluation and recommendations of representing ecological requirements in an optimisation framework

Metaheuristics are being increasingly used in optimisation studies for complex systems given their greater flexibility in problem formulation (Maier et al., 2014). However, the most appropriate optimisation algorithm is dependent upon the particular objectives, problem context, available information and modelling framework. Both metaheuristic and classical optimisation methods have been successfully applied to investigate improved ecological outcomes in river systems (e.g. Yeh and Becker, 1982; Shiau and Wu, 2006; Dittmann et al., 2009; Rheinheimer et al., 2013; Tsai et al., 2015). Irrespective of the algorithm used, of key importance is identifying the impact of different assumptions and uncertainties on results.

Although the impact of objective functions and decision variables has been widely discussed, it is rarely considered in the context of ecological objectives for river system management. Objective function formulation can affect whether greater focus is given to periods of good ecological conditions; to avoiding worst case scenarios; or to maintaining moderate conditions. The choice of decision variables can limit the type of management solutions found if they do not describe sufficient variability in flow release strategies, but can increase computational time as additional decision variables are introduced. It is recommended that the sensitivity of optimisation solutions to objective function and decision variable formulation is examined as part of any optimisation study, with particular consideration given to the ecological implications of different formulations.

\section{How well are ecological modelling outcomes evaluated in terms of actual outcomes?}

An assessment of actual ecological outcomes compared with modelled predictions is essential in the management of ecosystems, as well as in improving future modelling capabilities and understanding of the system (Davies et al., 2014). However, field-based evaluations of ecological outcomes are rarely reported in river system optimisation studies due to: the large investments needed; the lag time in ecological response; monitoring not being robustly designed to detect change; and the challenge in attributing ecological outcomes to a specific action (Lindenmayer and Likens, 2010). Of the papers reviewed, none identified whether the modelled outcomes had been applied in practice, and hence the performance of the model relative to actual ecological response was not evaluated. This lack of evaluation in the context of the real system is seen as a major limitation in the assessment of model performance.

Where evaluation of model performance against actual ecological outcomes is not possible, a comprehensive and systematic analysis of the model and optimisation framework can aid in understanding the impact of uncertainty on management strategies. Such assessment should focus on major assumptions likely to significantly alter the resulting strategies, including assumptions in objective setting, model representation and application in an optimisation framework. This can lead to greater understanding of model behaviour and the context in which it can be applied. A key element 
of model evaluation is in identifying major assumptions (such as system conceptualisation) and how they are likely to alter the model outcomes and recommended management actions.

Frameworks and tools such as those described by Walker et al. (2003), Refsgaard et al. (2007), van der Keur et al. (2008), O'Hagan (2012) and Bastin et al. (2013) provide guidance on identifying critical model assumptions. Bennett et al. (2013) also summarise and categorise a range of model evaluation metrics and methods. Of the optimisation papers reviewed, the majority did incorporate some sensitivity analysis (e.g. Sale et al., 1982; Xevi and Khan, 2005; Shiau and Wu, 2006; Shiau and Wu, 2009; Tilmant et al, 2010; Yang and Cai, 2011; Grafton et al, 2011; Yin et al, 2012; Jager, 2014). The majority of these papers examined sensitivity to different objective function weights, whilst others considered the impact of constraint values, decision variables and the optimisation algorithm. Some papers also tested the sensitivity to model parameters or input drivers, for example, the impact of different habitat functions (Sale et al., 1982), ecological model input parameters (Jager, 2014), different economic values for a wetland (Tilmant et al., 2010), and the impact of different water availability or allocations (Grafton et al., 2011; Szemis et al., 2012).

The application of robust optimisation and decision making can also incorporate model uncertainty through the use of multiple scenarios, where optimisation outcomes are evaluated against a range of possible futures to assess sensitivity to different assumptions (e.g. Lempert, 2002; Lempert et al., 2003; Deb and Gupta, 2006; Lempert and Groves, 2010; Hall et al., 2012; Kasprzyk et al., 2013).

We argue that a greater focus on comparing results to actual ecological outcomes is critical for bridging the gap between research and management, and for more informed application of modelling tools. This can be assisted through ongoing adaptive management, where different strategies are tested and evaluated, and used to improve future model predictions. This requires models to be adaptable to incorporate new information as it becomes available.

\section{Key Outcomes and Recommendations}

Using optimisation for ecological management in river systems presents both opportunities and challenges. Opportunities lie in the exploration of system behaviour and the facilitation of learning, communication, and ultimately decision making (Liebman, 1976; Brill Jr, 1979; Maier et al., 2014). Optimisation can increase transparency in the decision making process, encompass multiple stakeholder inputs and perspectives, as well as highlight data and knowledge gaps for future research. It provides a framework for formulating assumptions, and can be used in an iterative and adaptive process in conjunction with sources of information that are not directly included within the model.

Many of the challenges in using optimisation stem from the subjectivity in defining and representing objectives and objective functions, and the gaps in contemporary knowledge describing ecological systems. Given subjectivity is an inherent component of objective setting, better 
recognition of this subjectivity and its role in the decision making process can assist in identifying appropriate management strategies (Beven, 2002; Loucks, 2006). The issues pertaining to ecological systems discussed in this paper apply more widely, displaying characteristics of 'wicked problems' as identified by Rittel and Webber (1973).

This synthesis explored the use of optimisation for the management of riverine ecosystems by drawing upon papers covering a range of ecological modelling and optimisation approaches. Whilst previous studies demonstrate innovative ways of incorporating ecological objectives to improve river system management, this paper argues that more critical analysis is needed to examine how the objectives, model(s), optimisation approach, and results represent and influence ecological outcomes. Few previous studies critically evaluated the major assumptions throughout the optimisation process, and there was limited discussion regarding the impact of these assumptions on modelled solutions. In addition, there is a lack of evaluation of modelling results against actual ecological outcomes, which is considered necessary to further advance the effectiveness of optimisation to aid decision making.

Whilst many of the challenges identified in this synthesis are not unique to ecological systems, additional challenges are introduced due to the complexity and uncertainty inherent in understanding ecosystem behaviour, the social values attached to defining desirable ecological states, and the difficulty in measuring cause/effect relationships to evaluate outcomes (Davis and Slobodkin, 2004; Naiman et al., 2008). Many non-ecological water requirements such as for domestic, agricultural, or hydropower purposes are more easily estimated due to less variability in demands, and greater control through systems which are designed, constructed and operated to meet these requirements. In comparison, ecosystems change and adapt in response to prevailing conditions in ways that are generally less predictable (Holling, 1973). In addition, valuation of non-ecological objectives such as irrigation net profit or flood damage is often more straightforward than valuing an ecosystem.

The following recommendations draw on approaches for applying best practice for environmental modelling (e.g. Jakeman et al., 2006; Loucks, 2006), but with greater focus on identifying assumptions and uncertainties for optimisation:

(1) Identifying ecological objectives which consider both the overarching goal as well as the specific objective which is modelled and measured. It is recommended that the assumptions required in specifying these objectives are explored, as well as the role of social values in defining desired ecological outcomes.

(2) Further evaluation of the impact of limitations and assumptions on modelled outcomes, and consequently how well the modelled results can inform the stated objectives. It is recommended that the evaluation includes an assessment of the indicators used, and the use of multiple scenarios to identify the impact of different model conceptualisations.

(3) Consideration of the impact of objective functions and decision variables on ecological outcome. It is recommended that multiple formulations are tested as part of any optimisation study. 
(4) Evaluation of results within the context of assumptions in objective setting and problem formulation, with greater consideration of likely actual ecological outcomes. This type of evaluation can also assist in identifying requirements for additional data collection/investigations to improve the reliability of results.

The process of setting objectives through to evaluating results needs to be adaptive and allow for multiple iterations as the understanding of the system improves throughout the modelling and optimisation process, as well as over time (Loucks, 2006). In addition, there is a need for better integration of modelling and optimisation in the decision making process such that these tools can be tailored to the specific context, and can be complementary to other sources of information. It is believed that the above recommendations can improve the effectiveness of optimisation to aid decision making, both in terms of exploring different options which warrant further investigation, and in better understanding the system (Liebman, 1976; Brill Jr, 1979). The use of optimisation as part of a process that informs and enriches decision making rather than a purely predictive tool, allows the appreciation of limitations and uncertainties to be shared among stakeholders, thereby facilitating more widely acceptable decisions (Dunn et al., 2008; Gupta and Nearing, 2014).

\section{Acknowledgements}

The authors would like to thank those who have provided invaluable feedback on the manuscript, in particular Kerrie Tomkins, Holger Maier, and all anonymous reviewers. E. Barbour was supported by an Australian Postgraduate Award and by the National Centre for Groundwater Research and Training, Australia.

\section{References}

Ackoff, R. L., 1962. Some unsolved problems in problem solving, OR, 13(1): 1-11.

Acreman, M. C., Overton, I. C., King, J., Wood, P. J., Cowx, I. G., Dunbar, M. J., Kendy, E. and Young, W. J., 2014a. The changing role of ecohydrological science in guiding environmental flows, Hydrological Sciences Journal, 59(3-4): 433-450. doi: 10.1080/02626667.2014.886019

Acreman, M. C., Arthington, A. H., Colloff, M. J., Couch, C., Crossman, N. D., Dyer, F., Overton, I. C., Pollino, C. A., Stewardson, M. J. and Young, W., 2014b. Environmental flows for natural, hybrid and novel riverine ecosystems in a changing world, Frontiers in Ecology and the Environment, 12(8): 466 - 473. doi: 10.1890/130134

Arthington, A. H., Bunn, S. E., Poff, N. L. and Naiman, R. J., 2006. The challenge of providing environmental flow rules to sustain river ecosystems, Ecological Applications, 16(4): 1311 1318.

Baker, D. B., Richards, R. P., Loftus, T. T. and Kramer, J. W., 2004. A new flashiness index: characteristics and applications to midwestern rivers and streams, Journal of the American Water Resources Association, 40(2): 503-522. 
Bastin, L., Cornford, D., Jones, R., Heuvelink, G. B. M., Pebesma, E., Stasch, C., Nativi, S., Mazzetti, P. and Williams, M., 2013. Managing uncertainty in integrated environmental modelling: The UncertWeb framework, Environmental Modelling \& Software, 39: 116-134. doi: 10.1016/j.envsoft.2012.02.008

Bennett, N. D., Croke, B. F. W., Guariso, G., Guillaume, J. H. A., Hamilton, S. H., Jakeman, A. J., Marsili-Libelli, S., Newham, L. T. H., Norton, J. P., Perrin, C., Pierce, S. A., Robson, B., Seppelt, R., Voinov, A. A., Fath, B. D. and Andreassian, V., 2013. Characterising performance of environmental models, Environmental Modelling \& Software, 40: 1-20. doi: 10.1016/j.envsoft.2012.09.011

Bevelhimer, M. S., McManamay, R. A. and O'Connor, B., 2015. Characterizing sub-daily flow regimes: implications of hydrologic resolution on ecohydrology studies, River Research and Applications, 31(7): 867-879. doi: 10.1002/rra.2781

Beven, K., 2002. Towards a coherent philosophy for modelling the environment, Proceedings of the Royal Society, 458(2026): 2465-2484. doi: 10.1098/rspa.2002.0986

Biegler, L. T. and Grossmann, I. E., 2004. Retrospective on optimization, Computers and Chemical Engineering, 28(8): 1169-1192. doi: 10.1016/j.compchemeng.2003.11.003

Boulton, A. J., 1999. An overview of river health assessment: philosophies, practice, problems and prognosis, Freshwater Biology, 41(2): 469-479. doi: 10.1046/j.1365-2427.1999.00443.x

Brill Jr, E. D., 1979. The use of optimization models in public-sector planning, Management Science, 25(5): 413-422.

Bunn, S. E., Abal, E. G., Smith, M. J., Choy, S. C., Fellows, C. S., Harch, B. D., Kennard, M. J. and Sheldon, F., 2010. Integration of science and monitoring of river ecosystem health to guide investments in catchment protection and rehabilitation, Freshwater Biology, 55: 223-240. doi: 10.1111/j.1365-2427.2009.02375.x

Bunn, S. E. and Arthington, A. H., 2002. Basic principles and ecological consequences of altered flow regimes for aquatic biodiversity, Environmental Management, 30(4): 492 - 507. doi: 10.1007/s00267-002-2737-0

Costanza, R., d'Arge, R., de Groot, R., Farber, S., Grasso, M., Hannon, B., Limburg, K., Naeem, S., O'Neill, R. V., Paruelo, J., Raskin, R. G., Sutton, P. and van den Belt, M., 1997. The value of the world's ecosystem services and natural capital, Nature, 387(6630): 253-260.

Cropp, R. and Gabric, A., 2002. Ecosystem adaptation: Do ecosystems maximise resilience?, Ecology, 83(7): 2019-2026. doi: 10.1890/0012-9658(2002)083[2019:eademr]2.0.co;2

Cushman, R. M., 1985. Review of ecological effects of rapidly varying flows downstream from hydroelectric facilities, North American Journal of Fisheries Management, 5(3A): 330-339. doi: 10.1577/1548-8659(1985)5<330:roeeor>2.0.co;2

Davies, P. E., Harris, J. H., Hillman, T. J. and Walker, K. F., 2010. The Sustainable Rivers Audit: assessing river ecosystem health in the Murray-Darling Basin, Australia, Marine and Freshwater Research, 61(7): 764-777. doi: 10.1071/MF09043

Davis, M. A. and Slobodkin, L. B., (2004). The science and values of restoration ecology. Restoration Ecology, 12(1): 1-3. doi: 10.1111/j.1061-2971.2004.0351.x

Deb, K. and Gupta, H., 2006. Introducing robustness in multi-objective optimization, Evolutionary Computation, 14(4): 463-494. doi: 10.1162/evco.2006.14.4.463

Dittmann, R., Froehlich, F., Pohl, R. and Ostrowski, M., 2009. Optimum multi-objective reservoir operation with emphasis on flood control and ecology, Natural Hazards and Earth System Sciences, 9(6): 1973 - 1980.

Dunn, S. M., Freer, J., Weiler, M., Kirkby, M. J., Seibert, J., Quinn, P. F., Lischeid, G., Tetzlaff, D. and Soulsby, C., 2008. Conceptualization in catchment modelling: simply learning?, Hydrological Processes, 22(13): 2389-2393. doi: 10.1002/hyp.7070

Ellison, A., M., 1996. An Introduction to Bayesian Inference for Ecological Research and Environmental Decision-Making, Ecological Applications, 6(4): 1036-1046. doi: $10.2307 / 2269588$

Failing, L. and Gregory, R., 2003. Ten common mistakes in designing biodiversity indicators for forest policy, Journal of Environmental Management, 68(2): 121-132. doi: 10.1016/S03014797(03)00014-8 
Finn, M. and Jackson, S., 2011. Protecting indigenous values in water management: a challenge to conventional environmental flow assessments, Ecosystems, 14(8): 1232-1248. doi: 10.1007/s10021-011-9476-0

Fischer, J., Peterson, G. D., Gardner, T. A., Gordon, L. J., Fazey, I., Elmqvist, T., Felton, A., Folke, C. and Dovers, S., 2009. Integrating resilience thinking and optimisation for conservation, Trends in Ecology and Evolution, 24(10): 549 - 554. doi: 10.1016/j.tree.2009.03.020

Fisher, B., Turner, R. K. and Morling, P., 2009. Defining and classifying ecosystem services for decision making, Ecological Economics, 68(3): 643-653. doi: 10.1016/j.ecolecon.2008.09.014

Game, E. T., Watts, M. E., Wooldridge, S. and Possingham, H. P., 2008. Planning for persistence in marine reserves: a question of catastrophic importance, Ecological Applications 18(3): 670680. doi: $10.2307 / 40062177$

Game, E. T., Meijaard, E., Sheil, D. and McDonald-Madden, E., 2014. Conservation in a wicked complex world; challenges and solutions, Conservation Letters, 7(3): 271-277. doi: $10.1111 /$ conl.12050

Grafton, R. Q., Chu, H. L., Stewardson, M. and Kompas, T., 2011. Optimal dynamic water allocation: Irrigation extractions and environmental tradeoffs in the Murray River, Australia, Water Resour. Res., 47: W00G08. doi: 10.1029/2010wr009786

Gupta, H. V. and Nearing, G. S., 2014. Debates-The future of hydrological sciences: A (common) path forward? Using models and data to learn: A systems theoretic perspective on the future of hydrological science, Water Resources Research, 50(6): 5351-5359. doi: 10.1002/2013wr015096

Haas, N. A., O'Connor, B. L., Hayse, J. W., Bevelhimer, M. S. \& Endreny, T. A., 2014. Analysis of daily peaking and run-of-river operations with flow variability metrics, considering subdaily to seasonal time scales, Journal of the American Water Resources Association, 50(6): 16221640. doi: 10.1111/jawr.12228

Haimes, Y. Y. and Hall, W. A., 1977. Sensitivity, responsivity, stability and irreversibility as multiple objectives in civil systems, Advances in Water Resources, 1(2): 71-81.

Hall, J. W., Lempert, R. J., Keller, K., Hackbarth, A., Mijere, C. and McInerney, D. J., 2012. Robust climate policies under uncertainty: a comparison of robust decision making and info-gap methods, Risk Analysis, 32(10): 1657-1672. doi: 10.1111/j.1539-6924.2012.01802.x

Higgins, A. J., Bryan, B. A., Overton, I. C., Holland, K., Lester, R. E., King, D., Nolan, M. and Connor, J. D., 2011. Integrated modelling of cost-effective siting and operation of flowcontrol infrastructure for river ecosystem conservation, Water Resources Research, 47. W05519, doi: 10.1029/2010wr009919

Hirsch, P. D., Adams, W. M., Brosius, J. P., Zia, A., Bariola, N., and Dammert, J. L., 2011. Acknowledging conservation trade-offs and embracing complexity, Conservation Biology 25(2): 259-264, doi: 10.1111/j.1523-1739.2010.01608.x

Hitch, C., 1960. On the Choice of Objectives in System Studies.Santa Monica, CA, The RAND Corporation.

Hobbs, R. J., Arico, S., Aronson, J., Baron, J. S., Bridgewater, P., Cramer, V. A., Epstein, P. R., Ewel, J. J., Klink, C. A., Lugo, A. E., Norton, D., Ojima, D., Richardson, D. M., Sanderson, E. W., Valladares, F., Vilà, M., Zamora, R. and Zobel, M., 2006. Novel ecosystems: theoretical and management aspects of the new ecological world order, Global Ecology and Biogeography, 15(1): 1-7. doi: 10.1111/j.1466-822X.2006.00212.x

Hobbs, R. J., Higgs, E. and Harris, J. A., 2009. Novel ecosystems: implications for conservation and restoration, Trends in Ecology \& Evolution, 24(11): 599-605. doi: 10.1016/j.tree.2009.05.012

Holling, C. S., 1973. Resilience and stability of ecological systems, Annual Review of Ecology and Systematics, 4: 1-23. doi: 10.1146/annurev.es.04.110173.000245

Hurford, A. P., Huskova, I. and Harou, J.J. (2014). Using many-objective trade-off analysis to help dams promote economic development, protect the poor and enhance ecological health. Environmental Science and Policy, 38: 72-86. doi: 10.1016/j.envsci.2013.10.003

Jackson, S., 2006. Compartmentalising culture: the articulation and consideration of Indigenous values in water resource management, Australian Geographer, 37(1): 19-31. doi: 10.1080/00049180500511947 
Jackson, S., Pollino, C., Maclean, K., Bark, R. and Moggridge, B., 2015. Meeting Indigenous peoples' objectives in environmental flow assessments: Case studies from an Australian multijurisdictional water sharing initiative, Journal of Hydrology, 522: 141-151. doi: 10.1016/j.jhydrol.2014.12.047

Jacoby, H. D. and Loucks, D. P., 1972. Combined use of optimization and simulation models in river basin planning, Water Resources Research, 8(6): 1401-1414. doi: 10.1029/WR008i006p01401

Jager, H. I., 2014. Thinking outside the channel: Timing pulse flows to benefit salmon via indirect pathways, Ecological Modelling, 273: 117-127.10.1016/j.ecolmodel.2013.11.007

Jager, H. I. and Rose, K. A., 2003. Designing optimal flow patterns for fall Chinook salmon in a central valley, California, river, North American Journal of Fisheries Management, 23(1): 121.10.1577/1548-8675(2003)023<0001:dofpff >2.0.co;2

Jager, H. I. and Smith, B. T., 2008. Sustainable reservoir operation: can we generate hydropower and preserve ecosystem values?, River Research and Applications, 24(3): 340-352. doi: 10.1002/rra.1069

Jakeman, A. J., Letcher, R. A. and Norton, J. P., 2006. Ten iterative steps in development and evaluation of environmental models, Environmental Modelling \& Software, 21(5): 602-614. doi: 10.1016/j.envsoft.2006.01.004

Karr, J. R., 1999. Defining and measuring river health, Freshwater Biology, 41(2): 221-234. doi: 10.1046/j.1365-2427.1999.00427.x

Kasprzyk, J. R., Nataraj, S., Reed, P. M. and Lempert, R. J., 2013. Many objective robust decision making for complex environmental systems undergoing change, Environmental Modelling \& Software, 42: 55-71. doi: 10.1016/j.envsoft.2012.12.007

Kasprzyk, J. R., Reed, P. M., Characklis, G. W. and Kirsch, B. R., 2012. Many-objective de Novo water supply portfolio planning under deep uncertainty, Environmental Modelling \& Software, 34: 87-104. doi: 10.1016/j.envsoft.2011.04.003

Labadie, J. W., 2004. Optimal operation of multireservoir systems: state-of-the-art review, Journal of Water Resources Planning and Management, 130(2): 93-111.

Lackey, R. T., 2001. Values, Policy, and Ecosystem Health, Bioscience, 51(6): 437-443. doi: 10.1641/0006-3568(2001)051[0437:vpaeh]2.0.co;2

Lancaster, J., 2000. The ridiculous notion of assessing ecological health and identifying the useful concepts underneath, Human and Ecological Risk Assessment, 6(2): 213-222. doi: $10.1080 / 10807030009380056$

Lee, J. H. and Iwasa, Y., 2014. Modeling socio-economic aspects of ecosystem management and biodiversity conservation, Population Ecology 56(1): 27-40. doi: 10.1007/s10144-013-0423-0

Lempert, R. J., 2002. A new decision sciences for complex systems, Proceedings of the National Academy of Sciences of the United States of America, 99: 7309-7313. doi: 10.1073/pnas.082081699

Lempert, R. J. and Groves, D. G., 2010. Identifying and evaluating robust adaptive policy responses to climate change for water management agencies in the American west, Technological Forecasting and Social Change, 77(6): 960-974. doi: 10.1016/j.techfore.2010.04.007

Lempert, R. J., Popper, S. W. and Bankes, S. C., 2003. Shaping the Next One Hundred Years: Methods for Quantitative, Long-term Policy Analysis, RAND, Santa Monica, CA.

Liebman, J. C., 1976. Some simple-minded observations on role of optimization in public systems decision-making, Interfaces, 6(4): 102-108. doi: 10.1287/inte.6.4.102

Lindenmayer, D. B. and Likens, G. E., 2010. The science and application of ecological monitoring, Biological Conservation, 143(6): 1317-1328. doi: 10.1016/j.biocon.2010.02.013

Loucks, D. P., 2006. Modeling and managing the interactions between hydrology, ecology and economics, Journal of Hydrology, 328(3-4): 408-416. doi: 10.1016/j.jhydrol.2005.12.020

Maier, H. R., Kapelan, Z., Kasprzyk, J., Kollat, J., Matott, L. S., Cunha, M. C., Dandy, G., Gibbs, M. S., Keedwell, E., Marchi, A., Ostfeld, A., Savic, D., Solomatine, D. P., Vrugt, J. A., Zecchin, A. C., Minsker, B. S., Barbour, E. J., Kuczera, G. and Pasha, F., 2014. Evolutionary algorithms and other metaheuristics in water resources: current status, research challenges and future directions, Environmental Modelling \& Software, 62: 271-299 
Matott, L. S., Babendreier, J. E. and Purucker, S. T., 2009. Evaluating uncertainty in integrated environmental models: A review of concepts and tools, Water Resources Research, 45(6): W06421.doi: 10.1029/2008WR007301

Metrick, A. and Weitzman, M. L., 1998. Conflicts and choices in biodiversity preservation, Journal of Economic Perspectives 12(3): 21-34. doi: 10.1257/jep.12.3.21

Naiman, R. J., Latterell, J. J., Pettit, N. E. and Olden, J. D., 2008. Flow variability and the biophysical vitality of river systems, Comptes Rendus Geoscience, 340(9-10): 629-643. doi: 10.1016/j.crte.2008.01.002

Nicklow, J., Reed, P., Savic, D., Dessalegne, T., Harrell, L., Chan-Hilton, A., Karamouz, M., Minsker, B., Ostfeld, A., Singh, A. and Zechman, E., 2010. State of the art for genetic algorithms and beyond in water resources planning and management, Journal of Water Resources Planning and Management, 136(4): 412 - 432.

Nicholson, E. and Possingham, H. P., 2006. Objectives for multiple-species conservation planning. Conservation Biology, 20(3): 871-881. doi: 10.1111/j.1523-1739.2006.00369.x

Nicholson, E., Westphal, M. I., Frank, K., Rochester, W. A., Pressey, R. L., Lindenmayer, D. B. and Possingham, H. P., 2006. A new method for conservation planning for the persistence of multiple species, Ecology Letters 9(9): 1049-1060. doi: 10.1111/j.1461-0248.2006.00956.x

Nicholson, E. and Possingham, H. P., 2007. Making conservation decisions under uncertainty for the persistence of multiple species, Ecological Applications 17(1): 251-265. doi: $10.2307 / 40061991$

Norris, R. H. and Thoms, M. C., 1999. What is river health?, Freshwater Biology, 41(2): 197-209. doi: 10.1046/j.1365-2427.1999.00425.x

Norton, J. P. and Andrews, F. T., 2006. Sensitivity and structure assessment of a software tool to gauge the ecological impact of flow scenarios, Journal of Hydrology, 325(1-4): 325339.10.1016/j.jhydrol.2005.10.035

O'Hagan, A., 2012. Probabilistic uncertainty specification: Overview, elaboration techniques and their application to a mechanistic model of carbon flux, Environmental Modelling \& Software, 36: 35-48. doi: 10.1016/j.envsoft.2011.03.003

Olivares, M. A., Haas, J., Palma-Behnke, R. and Benavides, C., 2015. A framework to identify Pareto-efficient subdaily environmental flow constraints on hydropower reservoirs using a grid-wide power dispatch model, Water Resources Research, 51(5): 36643680.10.1002/2014wr016215Pahl-Wostl, C., Arthington, A., Bogardi, J., Bunn, S. E., Hoff, H., Lebel, L., Nikitina, E., Palmer, M., Poff, L. N., Richards, K., Schlüter, M., Schulze, R., St-Hilaire, A., Tharme, R., Tockner, K. and Tsegai, D., 2013. Environmental flows and water governance: managing sustainable water uses, Current Opinion in Environmental Sustainability, 5(3-4): 341-351. doi: 10.1016/j.cosust.2013.06.009

Palmer, M. A., Bernhardt, E. S., Allan, J. D., Lake, P. S., Alexander, G., Brooks, S., Carr, J., Clayton, S., Dahm, C.N., Follstad Shah, J., Galat, D. L., Loss, S. G., Goodwin, P., Hart, D. D., Hassett, B., Jenkinson, R., Kondolf, G. M., Lave, R., Meyer, J. L., O’Donnell, T. K., Pagano, L., and Sudduth, E., 2005. Standards for ecologically sucessful river restoration. Journal of Applied Ecology, 42(2): 208-217. doi: 10.1111/j.1365-2664.2005.01004.x

Poff, N. L., Allan, J. D., Bain, M. B., Karr, J. R., Prestegaard, K. L., Richter, B. D., Sparks, R. E. and Stromberg, J. C., 1997. The natural flow regime, Bioscience, 47(11): 769-784.

Poff, N. L., Richter, B. D., Arthington, A. H., Bunn, S. E., Naiman, R. J., Kendy, E., Acreman, M., Apse, C., Bledsoe, B. P., Freeman, M. C., Henriksen, J., Jacobson, R. B., Kennen, J. G., Merritt, D. M., O’Keeffe, J. H., Olden, J. D., Rogers, K., Tharme, R. E. and Warner, A., 2010. The ecological limits of hydrologic alteration (ELOHA): a new framework for developing regional environmental flow standards, Freshwater Biology, 55(1): 147-170. doi: 10.1111/j.1365-2427.2009.02204.x

Poff, N. L. and Matthews, J. H., 2013. Environmental flows in the Anthropocence: past progress and future prospects, Current Opinion in Environmental Sustainability, 5(6): 667-675. doi: 10.1016/j.cosust.2013.11.006

Poiani, K. A., Richter, B. D., Anderson, M. G. and Richter, H. E., 2000. Biodiversity conservation at multiple scales: functional sites, landscapes, and networks, Bioscience, 50(2): 133 - 146. 
Possingham, H. P., Andelman, S. J., Noon, B. R., Trombulak, S., Pulliam, H. R., 2001. Making smart conservation decisions. In: Soulé, M. E. and Orians, G. H. (Eds). Conservation biology: research priorities for the next decade, 225-244. Island Press. Washington D.C.

Probert, W. J. M., Hauser, C. E., McDonald-Madden, E., Runge, M. C., Baxter, P. W. J. and Possingham, H. P., 2011. Managing and learning with multiple models: Objectives and optimization algorithms, Biological Conservation, 144(4): 1237-1245. doi: http://dx.doi.org/10.1016/j.biocon.2010.07.031

Rapport, D. J., 1989. What constitutes ecosystem health, Perspectives in Biology and Medicine, 33(1): 120-132.

Reed, P. M. and Kasprzyk, J., 2009. Water resources management: the myth, the wicked, and the future, Journal of Water Resources Planning and Management, 135(6): 411-413.

Refsgaard, J. C., van der Sluijs, J. P., Hojberg, A. L. and Vanrolleghem, P. A., 2007. Uncertainty in the environmental modelling process - A framework and guidance, Environmental Modelling \& Software, 22(11): 1543-1556. doi: 10.1016/j.envost.2007.02.004

Rheinheimer, D. E., Yarnell, S. M. and Viers, J. H., 2013. Hydropower costs of environmental flows and climate warming in California's Upper Yuba River watershed, River Research and Applications, 29(10): 1291-1305. doi: 10.1002/rra.2612

Richter, B., Baumgartner, J., Wigington, R. and Braun, D., 1997. How much water does a river need?, Freshwater Biology, 37(1): 231-249. doi: 10.1046/j.1365-2427.1997.00153.x

Richter, B. D., Baumgartner, J. V., Powell, J. and Braun, D. P., 1996. A method for assessing hydrologic alteration within ecosystems, Conservation Biology, 10(4): 1163-1174. doi: 10.1046/j.1523-1739.1996.10041163.x

Richter, B. D., Mathews, R., Harrison, D. L. and Wigington, R., 2003. Ecologically sustainable water management: managing river flows for ecological integrity, Ecological Applications, 13(1): 206-224.

Richter, B. D., Warner, A. T., Meyer, J. L. and Lutz, K., 2006. A collaborative and adaptive process for developing environmental flow recommendations, River Research and Applications, 22(3): 297-318. doi:10.1002/rra.892

Ringler, C. and Cai, X. M., 2006. Valuing fisheries and wetlands using integrated economichydrologic modeling - Mekong River Basin, Journal of Water Resources Planning and Management-Asce, 132(6): 480-487.10.1061/(asce)0733-9496(2006)132:6(480)

Rittel, H., W. J. and Webber, M., M., 1973. Dilemmas in a General Theory of Planning, Policy Sciences, 4(2): 155-169.

Rogers, K., Ralph, T. J. and Saintilan, N., 2012. The use of representative species as surrogates for wetland inundation, Wetlands, 32: 249-256. doi: 10.1007/s13157-012-0285-9

Sale, M. J., Brill, E. D., Jr. and Herricks, E. E., 1982. An approach to optimizing reservoir operation for downstream aquatic resources, Water Resources Research, 18(4): 705-712. doi: 10.1029/WR018i004p00705

Sarkar, S., Pressey, R. L., Faith, D. P., Margules, C. R., Fuller, T., Stoms, D. M., Moffett, A., Wilson, K. A., Williams, K. J., Williams, P. H. and Adelman, S., 2006. Biodiversity conservation planning tools: present status and challenges for the future. Annual Review of Environment and Resources, 31: 123-159. doi: 10.1146/annurev.energy.31.042606.085844

Shannon, C. E., 1948. A mathematical theory of communication, Bell System Technical Journal, 27(3): 379-423; 623-656

Shenton, W., Bond, N. R., Yen, J. D. L. and Mac Nally, R., 2012. Putting the "ecology" into environmental flows: ecological dynamics and demographic modelling, Environmental Management, 50: 1-10

Shiau, J. T. and Wu, F. C., 2006. Compromise programming methodology for determining instream flow under multiobjective water allocation criteria, Journal of the American Water Resources Association, 42(5): 1179-1191.

Shiau, J. T. and Wu, F. C., 2008. A histogram matching approach for assessment of flow regime alteration: application to environmental flow optimization, River Research and Applications, 24(7): 914-928. doi: 10.1002/rra.1102 
Shiau, J. T. and Wu, F. C., 2009. Regionalization of natural flow regime: application to environmental flow optimization at ungauged sites, River Research and Applications, 25(9): 1071-1089. doi: $10.1002 /$ rra. 1207

Shiau, J.T., and F.C. Wu, 2013. Optimizing environmental flows for multiple reaches affected by a multipurpose reservoir system in Taiwan: Restoring natural flow regimes at multiple temporal scales, Water Resources Research, 49, doi:10.1029/2012WR012638.

Steedman, R. J., 1994. Ecosystem health as a management goal, Journal of the North American Benthological Society, 13(4): 605-610. doi: 10.2307/1467856

Suen, J.P. and Eheart, J. W., 2006. Reservoir management to balance ecosystem and human needs: Incorporating the paradigm of the ecological flow regime, Water Resources Research, 42(3): W03417. doi: 10.1029/2005wr004314

Suen, J. P., Eheart, J. W., Herricks, E. E. and Chang, F. J., 2009. Evaluating the Potential Impact of Reservoir Operation on Fish Communities, Journal of Water Resources Planning and Management-Asce, 135(6): 475-483. doi: 10.1061/(asce)0733-9496(2009)135:6(475)

Suter, G. W., 1993. A critique of ecosystem health concepts and indexes, Environmental Toxicology and Chemistry, 12(9): 1533-1539. doi: 10.1002/etc.5620120903

Szemis, J. M., Maier, H. R. and Dandy, G. C., 2012. A framework for using ant colony optimization to schedule environmental flow management alternatives for rivers, wetlands and floodplains, Water Resources Research, 48: W08502. doi:10.1029/2011WR011276

Szemis, J. M., Maier, H. R. and Dandy, G. C., 2014. An adaptive ant colony optimization framework for scheduling environmental flow management alternatives under varied environmental water availability conditions, Water Resources Research, 50(10): 76067625.10.1002/2013WR015187

Tear, T. H., Kareiva, P., Angermeier, P. L., Comer, P., Czech, B., Kautz, R., Landon, L., Mehlman, D., Murphy, K., Ruckelshaus, M., Scott, J. M. and Wilhere, G., 2005. How much is enough? The recurrent problem of setting measurable objectives in conservation, Bioscience, 55(10): 835-849. doi: 10.1641/0006-3568(2005)055[0835:HMIETR]2.0.CO;2

Tilmant, A., Beevers, L. and Muyunda, B., 2010. Restoring a flow regime through the coordinated operation of a multireservoir system: The case of the Zambezi River basin, Water Resources Research, 46: 11. W07533, doi: 10.1029/2009wr008897

Tsai, W. P., Chang, F. J., Chang, L. C. and Herricks, E. E., 2015. AI techniques for optimizing multiobjective reservoir operation upon human and riverine ecosystem demands, Journal of Hydrology, 530: 634-644.10.1016/j.jhydrol.2015.10.024

van der Keur, P., Henriksen, H. J., Refsgaard, J. C., Brugnach, M., Pahl-Wostl, C., Dewulf, A. and Buiteveld, H., 2008. Identification of major sources of uncertainty in current IWRM practice. Illustrated for the Rhine Basin, Water Resources Management, 22(11): 1677-1708. doi: 10.1007/s11269-008-9248-6

Voinov, A. and Bousquet, F., 2010. Modelling with stakeholders, Environmental Modelling \& Software, 25(11): 1268-1281. doi: 10.1016/j.envsoft.2010.03.007

Walker, W. E., Harremoës, P., Rotmans, J., van der Sluijs, J. P., van Asselt, M. B. A., Janssen, P. and Krayer von Krauss, M. P., 2003. Defining uncertainty: A conceptual basis for uncertainty management in model-based decision support, Integrated Assessment, 4(1): 5-17. doi: 10.1076/iaij.4.1.5.16466

Walters, C. J. and Hilborn, R., 1978. Ecological optimization and adaptive management. Annual Review of Ecology and Systematics, 9: 157-188. doi: 10.1146/annurev.es.09.110178.001105

Wang, X., Sun, Y., Song, L. and Mei, C., 2009. An eco-environmental water demand based model for optimising water resources using hybrid genetic simulated annealing algorithms. Part 1. Model development, Journal of Environmental Management, 90: 2628 - 2635.

Wicklum, D. and Davies, R. W., 1995. Ecosystem health and integrity?, Canadian Journal of Botany, 73(7): 997-1000. doi: 10.1139/b95-108

Wilson, K. A., Carwardine, J. and Possingham, H. P., 2009. Setting Conservation Priorities, Annals of the New York Academy of Sciences, 1162(1): 237-264. doi: 10.1111/j.17496632.2009.04149.x

Xevi, E. and Khan, S., 2005. A multi-objective optimisation approach to water management, Journal of Environmental Management, 77: 269 -277. 
Yang, Y. and Cai, X., 2011. Reservoir reoperation for fish ecosystem restoration using daily inflows - case study of Lake Shelbyville, Journal of Water Resources Planning and Management, 137(6): 470-480. doi: 10.1061/(ASCE)WR.1943-5452.0000139

Yeh, W. W. G. and Becker, L., 1982. Multiobjective analysis of multireservoir operations, Water Resources Research, 18(5): 1326 - 1336.

Yin, X. A., Yang, Z. F. and Petts, G. E., 2012. Optimizing environmental flows below dams, River Research and Applications, 28(6): 703-716. doi: 10.1002/rra.1477

Young, W. J., Scott, A. C., Cuddy, S. M. and Rennie, B. A., 2003. Murray Flow Assessment Tool: A Technical Description. Report for CRC for Freshwater Ecology. CSIRO Land and Water.

Zimmerman, J. K. H., Letcher, B. H., Nislow, K. H., Lutz, K. A. and Magilligan, F. J., 2010.

Determining the effects of dams on subdaily variation in river flows at a whole-basin scale, River Research and Applications, 26(10): 1246-1260. doi: 10.1002/rra.1324 